University of Wollongong

Research Online

Faculty of Engineering - Papers (Archive)

Faculty of Engineering and Information

Sciences

March 2007

\title{
Constriction-Based Retention Criterion for Granular Filter Design
}

Buddhima Indraratna

University of Wollongong, indra@uow.edu.au

A. K. Raut

Snowy Mountains Engineering Corporation, North Sydney

H. Khabbaz

University of Wollongong, khabbaz@uow.edu.au

Follow this and additional works at: https://ro.uow.edu.au/engpapers

Part of the Engineering Commons

https://ro.uow.edu.au/engpapers/336

\section{Recommended Citation}

Indraratna, Buddhima; Raut, A. K.; and Khabbaz, H.: Constriction-Based Retention Criterion for Granular Filter Design 2007.

https://ro.uow.edu.au/engpapers/336

Research Online is the open access institutional repository for the University of Wollongong. For further information contact the UOW Library: research-pubs@uow.edu.au 


\title{
Constriction-Based Retention Criterion for Granular Filter Design
}

\author{
Buddhima Indraratna, F.ASCE${ }^{1}$; Ashok K. Raut ${ }^{2}$; and Hadi Khabbaz ${ }^{3}$
}

\begin{abstract}
The filter design criteria in practice are currently based on laboratory tests that were carried out on uniform base soil and filter materials. These criteria mostly involve specific particle size ratios, where the system of base soil and filter is represented by some characteristic particle sizes. Consequently, these criteria have limitations when applied to nonuniform materials. In filters, it is the constriction size rather than the particle size that affects filtration. In this paper, a mathematical procedure to determine the controlling constriction size is introduced, and subsequently, a constriction-based retention criterion for granular filters is presented. The model also incorporates the effect of nonuniformity of base soil in terms of its particle size distribution, considering the surface area of the particles. The proposed retention criterion is verified based on experimental data taken from past studies plus large-scale filtration tests carried out by the authors. The model successfully and distinctly demarcates the boundary between effective and ineffective filters in the case of cohensionless base soils.
\end{abstract}

DOI: 10.1061/(ASCE)1090-0241(2007)133:3(266)

CE Database subject headings: Filters; Design; Construction; Material properties.

\section{Introduction}

Although known to be conservative and originally developed for cohensionless uniform base soil and filter materials, the wellknown Terzaghi retention criterion (USACE 1953) is given by the relationship, $D_{15} / d_{85}<5$. Here, for the filter material, $15 \%$ by mass of particles are finer than the size denoted by $D_{15}$, and for the base soil, $85 \%$ by mass of particles are finer than the size denoted by $d_{85}$. Several past studies (e.g., Sherard et al. 1984a; Bertram 1940) revealed that filters even with higher values of retention ratio, $D_{15} / d_{85}$, can be effective, especially in the case of uniform base soils. In contrast, studies conducted by Lafleur (1984) demonstrated that some filters with retention ratios smaller than four involving nonuniform or well-graded base soils were ineffective. To address this effect of diminishing filter effectiveness in the case of well-graded base soils, the current design practice (NRCS 1994) recommends the use of $d_{85}$ after regrading the base soil PSD for particles larger than \#4 sieve size $(4.75 \mathrm{~mm})$, i.e., $d_{85 R}$ rather than the conventional $d_{85}$ without regrading. ICOLD (1994) also suggests the use of a smaller base soil representative size.

Honjo and Veneziano (1985) carried out a statistical analysis

${ }^{1}$ Professor of Civil Engineering, Univ. of Wollongong, Wollongong City, NSW 2522, Australia (corresponding author). E-mail: indra@ uow.edu.au

${ }^{2}$ Senior Water Engineer, Snowy Mountains Engineering Corporation, Level 6, 76 Berry St. North Sydney, NSW 2060, Australia.

${ }^{3}$ Lecturer, School of Civil Engineering, Univ. of Wollongong, Wollongong City, NSW 2522, Australia.

Note. Discussion open until August 1, 2007. Separate discussions must be submitted for individual papers. To extend the closing date by one month, a written request must be filed with the ASCE Managing Editor. The manuscript for this paper was submitted for review and possible publication on June 14, 2005; approved on September 26, 2006. This paper is part of the Journal of Geotechnical and Geoenvironmental Engineering, Vol. 133, No. 3, March 1, 2007. @ASCE, ISSN 1090-0241/ 2007/3-266-276/\$25.00. on various test data and found that the reliability of filters diminished for nonuniform base soils. However, such statistical analyses do not explain the fundamental physics of filtration, and are not always free from bias inherent in experimental procedures. For example, consider three different base soils (B1, B2, and B3) having the same $d_{85}$ tested against three different filters (F1, F2, and F3) having the same $D_{15}$ (Fig. 1). These base soil and filter arrangements have identical $D_{15} / d_{85}$ ratios. The question is whether these base soil-filter systems have similar filtration characteristics in terms of mass retention and flow rates. In other words, is the $D_{15} / d_{85}$ ratio on its own adequate to describe the filter effectiveness? Locke et al. (2001) highlighted that the evaluation of filter effectiveness based on the constriction size distribution is more appropriate than the sole use of particle sizes. This study is an attempt to present a constriction-based retention criterion valid for both uniform and well-graded materials supported by experimental evidence.

\section{Theoretical Concepts}

The main theoretical concepts describing the nature of constriction size distribution (CSD) of a filter have been addressed by Indraratna and Locke (2000), Raut and Indraratna (2004), and Locke et al. (2001). In this study, the authors have extended the above principles and have developed a computational procedure to determine the filter constriction size distribution (CSD) for a given particle size distribution (PSD) and relative density $\left(R_{d}\right)$. Some salient features of the constriction model are elucidated below.

\section{Constriction Sizes in the Densest and Loosest Particle Arrangements}

In a real granular filter, particles exist in a group of three or four, representing the densest and loosest arrangements, respectively. Humes (1996) assumed that in a filter at maximum density, only 


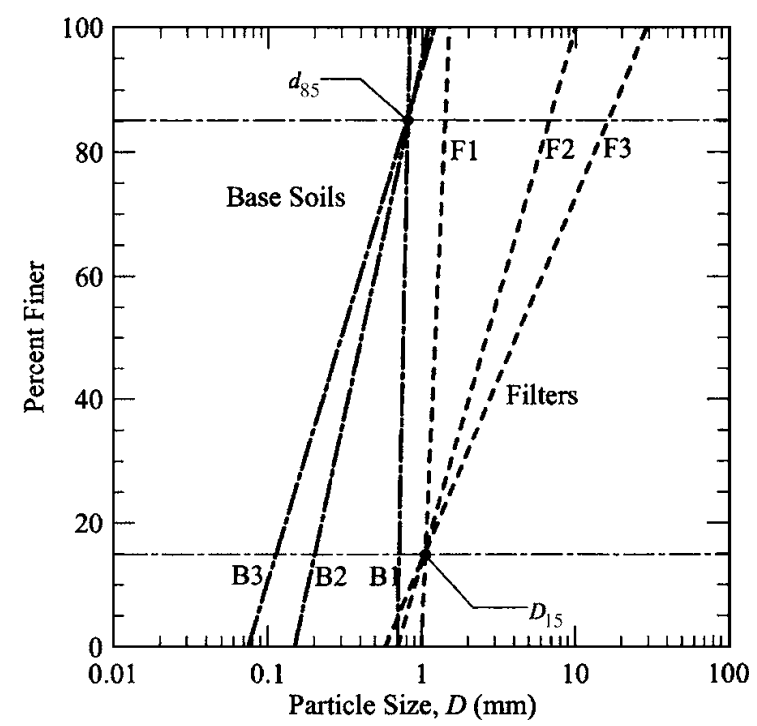

Fig. 1. Base soils and filters with various uniformity coefficients $\left(C_{u}\right)$ but having the same retention ratio $\left(D_{15} / d_{85}\right)$

the densest arrangements exist, and defined the constriction size $D_{c D}$ as the diameter of the largest circle that can fit within three tangent filter particles [Fig. 2(a)], which can be given by

$$
\begin{aligned}
& \left(\frac{2}{D_{1}}\right)^{2}+\left(\frac{2}{D_{2}}\right)^{2}+\left(\frac{2}{D_{3}}\right)^{2}+\left(\frac{2}{D_{c D}}\right)^{2} \\
& =0.5\left[\left(\frac{2}{D_{1}}\right)+\left(\frac{2}{D_{2}}\right)+\left(\frac{2}{D_{3}}\right)+\left(\frac{2}{D_{c D}}\right)\right]^{2}
\end{aligned}
$$

However, a real filter is not always compacted to its maximum density, which implies that the densest constriction model is conservative. For any general particle arrangement, the constriction space $S_{c}$ between four particles [Fig. 2(b)] is given by (Silveira 1975)

$$
\begin{aligned}
S_{c}= & \frac{1}{8}\left(\left(D_{1}+D_{2}\right)\left(D_{1}+D_{4}\right) \sin \alpha+\left(D_{2}+D_{3}\right)\left(D_{2}+D_{4}\right) \sin \gamma\right. \\
& \left.-\left(\alpha D_{1}^{2}+\beta D_{2}^{2}+\gamma D_{3}^{2}+\delta D_{4}^{2}\right)\right)
\end{aligned}
$$

where the angles $\beta, \gamma$, and $\delta$ can be related to $\alpha$ by plane geometry. The angle $\alpha$ varies between $\alpha_{\min }$ and $\alpha_{\max }$ [Figs. 2(c and d)]. For a particular value of $\alpha$ between these two extreme values, when the value of $S_{c}$ is maximum, then the corresponding con-

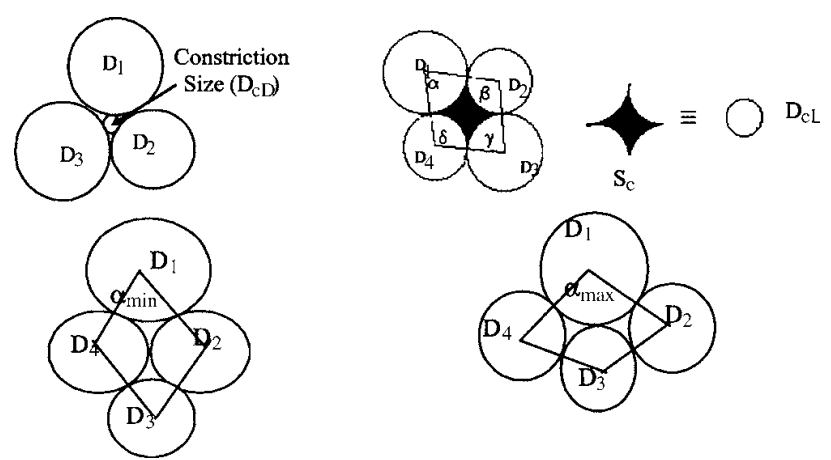

Fig. 2. Filter particle arrangements in (a) densest state; (b) loosest state; (c) minimum $\alpha$; and (d) maximum $\alpha$ (adapted from Silveira et al. 1975)

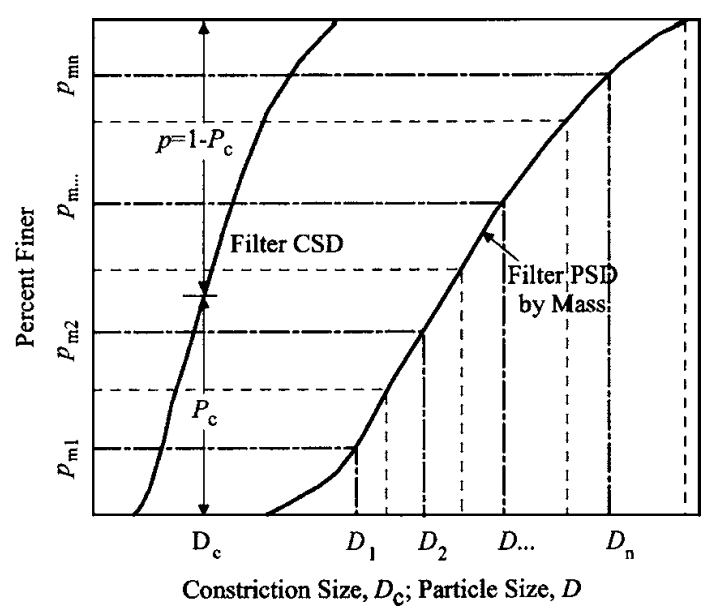

Fig. 3. A typical filter PSD and CSD showing passing probability $p\left(=1-P_{c}\right)$

striction size in the loosest arrangement based on equivalent diameter $D_{c L}$ is given by

$$
D_{c L}=\sqrt{\frac{4 S_{c, \max }}{\pi}}
$$

The probability of occurrence of $D_{c D}$ and $D_{c L}$ depends upon the probabilities of individual particles constituting the arrangements, and can be calculated statistically (Silveira 1975). If a filter PSD is divided into a number of particle sizes (Fig. 3), in the manner explained above, $D_{c D}$ and $D_{c L}$, and their corresponding probabilities can be determined for all possible unique combinations of particles in the densest and loosest states, resulting in the densest and loosest CSD models, i.e., CSD (D) and CSD (L).

\section{Particle Surface Area and Filter Compaction}

Most researchers have used the densest CSD, i.e., CSD (D) for simplicity, where the filter PSDs either by mass or by number of particles have been used. However, as explained by Locke et al. (2001), although PSD by mass obtained through sieve analysis is accepted as a good representation of constriction size distribution (CSD) for uniform filters, the use of PSD by mass introduces errors in well-graded filters. This is because large particles with a high individual mass but low in number will be over-represented, as it is unlikely that these few large particles will meet together to form a large constriction. In a similar manner, the PSD by number over-represents the finer constrictions. Humes (1996) suggested that although there are only a small number of large particles, they impose significant contact with other particles due to their larger surface area, and showed that the filter PSD based on surface area is the best option for filtration analysis.

If a filter material is composed of $n$ diameters, $D_{1}, D_{2}, D_{3}, \ldots, D_{n}$ and their mass probabilities of occurrence are $p_{m 1}, p_{m 2}, p_{m 3}, \ldots, p_{m n}$, respectively (Fig. 3 ), then their respective probabilities of occurrence by surface area $\left(p_{S A i}\right)$ can be obtained by (Humes 1996)

$$
p_{S A i}=\left(p_{m i} / D_{i}\right) /\left(\sum_{i=1}^{n} \frac{p_{m i}}{D}\right)
$$

Similarly, their probabilities of occurrence by number $\left(p_{N i}\right)$ can be obtained by (Raut and Indraratna 2004) 